\title{
(t)
}

\section{A QUESTÃO URBANA E A PRODUÇÃO ACADÊMICA DO SERVIÇO SOCIAL BRASILEIRO EM FOCO'}

\author{
The urban issue and the academic prodution \\ of Brazilian Social Work in focus
}

\section{Eliana Costa Guerra² Maria Clariça Ribeiro Guimarães 3 Raquel Cardozo da Silva ${ }^{4}$}

\section{RESUMO}

O artigo aborda a questão urbana como objeto de pesquisa do Serviço Social. Resulta de pesquisa teórica e de análise das produções sobre esta temática, tendo por base artigos dos anais dos Encontros Nacionais de Pesquisadores em Serviço Social (ENPESS), no período 2000-2010. A ampliação e diversidade de espaços sócio-ocupacionais não correspondem necessariamente ao desenvolvimento de pesquisas, com aprofundamento

\footnotetext{
1 Artigo resultante de esforços de pesquisa no âmbito do Projeto: "Questão Urbana, Agrária e Ambiental na atual fase de acumulação capitalista".

${ }^{2}$ Assistente social, doutora em sociologia pela Universidade Paris 8, Professora do Programa de Pós-Graduação em Serviço Social e do Departamento de Serviço Social da Universidade Federal do Rio Grande do Norte. E-mail: <elianacostaguerra@hotmail.com>

${ }^{3}$ Bacharel em Serviço Social pela Universidade do Estado do Rio Grande do Norte (UERN) e mestranda do Programa de Pós-Graduação em Serviço Social da Universidade Federal do Rio Grande do Norte (UFRN). Pesquisa, em seus estudos de mestrado, questão urbana, movimentos sociais e organização popular. E-mail: <clara_ama@yahoo.com.br>

${ }^{4}$ Estudante do curso de Serviço Social da Universidade Federal do Rio Grande do Norte (UFRN), bolsista de Iniciação Científica (Projeto Questão urbana e ambiental: um debate em aberto no âmbito da produção acadêmica do Serviço Social brasileiro). E-mail: <raquels-social@hotmail.com>.
} 
teórico-metodológico exigido pela complexidade da questão urbana na contemporaneidade. Há crescente interesse pela temática de pesquisadores, profissionais e estudantes e esforços de sistematização e pesquisa evidenciados no número de trabalhos e na busca de qualidade dos mesmos. Mas há também necessidade de aprofundamento teórico-metodológico para uma produção do conhecimento em consonância com o Projeto Ético-Politico, o que supõe construção de vias de superação da sociabilidade capitalista.

\section{PALAVRAS-CHAVE}

ENPESS. Serviço Social. Questão urbana. Capitalismo. Espaço. Segregação sócio-espacial.

\section{ABSTRACT}

The article discusses the urban question as a research subject of Social Work. It results from theoretical research and analysis of productions on this theme, more specifically, articles in the annals of the National Meeting of Researchers in Social Work (ENPESS) in the period 2000-2010. The expansion and diversity of socio-occupational areas do not necessarily correspond to the development of research, with further theoretical and methodological framework required by the complex contemporary urban question. There is growing interest in works by researchers, professionals and students and in the efforts to systematize and research shown in the number of papers and in the pursuit of quality. But there is also need for theoretical and methodological framework for knowledge production aligned with the ethical-political project, which involves the construction of ways to overcome the capitalist sociability.

\section{KEYWORDS}

ENPESS. Social Work. Urban issues. Capitalism. Space. Socio-spatial segregation.

Submetido: $15 / 6 / 2012$

Aceito: $11 / 9 / 2012$

\section{INTRODUÇÃO}

Ao pautar as temáticas "questão urbana”, "questão agrária” e "questão ambiental", nos principais eventos da categoria (Congresso Brasileiro de Assistentes Sociais e Encontro Nacional de Pesquisadores em Serviço Social), o Serviço Social brasileiro re- 
conhece a premência de uma discussão crítica sobre estas dimensões da questão social, objeto precípuo de intervenção e análise da profissão.

Para efeito de estudo, neste artigo, trataremos apenas da dimensão urbana da questão social, sem, entretanto, olvidarmos que questão urbana e questão agrária constituem pares dialéticos, portanto, inseparáveis, da totalidade social. Com efeito, nas cidades e nas zonas rurais, a dinâmica de desenvolvimento das forças produtivas engendra modos particulares de apropriação e uso do solo, de expropriação dos recursos naturais e da força de trabalho, além de formas de organização e de gestão do espaço produtoras de segregação e degradação da natureza e do homem.

Considerando as referidas temáticas como particularidades da questão social, nossa pesquisa se insere no esforço de problematização da produção acadêmica concernente à questão urbana, na tentativa de resgatar ferramentas do método em Marx para tratar do urbano numa perspectiva de totalidade. Significa que reconhecemos a indissociabilidade entre questão agrária e urbana, mas, igualmente, a existência de particularidades a serem explicitadas. Deste modo, apreender os mecanismos de reprodução do capital, a partir de sua lógica de acumulação, concentração e centralização nos permite entender os determinantes da dinâmica urbana no seio da qual se produzem, ao mesmo tempo, expressões da questão urbana, da questão agrária e ambiental. Ora, o desenvolvimento das forças produtivas permite formas de inversão de capitais no campo e na cidade, com vistas a alimentar o processo de acumulação capitalista. Tal processo acontece à custa de expropriações primárias e secundárias, que afetam sobremaneira os diversos segmentos da classe trabalhadora e incidem diretamente sobre suas condições de vida. Aprofundar este entendimento, sobretudo, na particularidade da realidade urbana, impôs-se como desafio incontornável.

O processo de investigação compreendeu pesquisa teórica e documental, seguida de leitura crítica e de análise do material coletado. Partimos de referências sobre a questão urbana, seus determinantes, suas diferentes dimensões para, em seguida, tratar da particularidade do espaço urbano no âmbito da sociedade brasileira. 
Para fundamentar a análise das produções e os recortes que a categoria vem operando em suas elaborações, procedemos à coleta de materiais para realização do "estado da arte". Com pesquisa nos anais de Encontro Nacional de Serviço Social (ENPESS)5, realizados nos últimos dez anos (2000; 2002; 2004; 2006; 2008 e 2010), coletamos e sistematizamos a produção da categoria socializada no principal evento de pesquisa da área de Serviço Social. O material em apreço refere-se ao VII, VIII, IX, X, XI e XII ENPESS, os quais foram realizados em Brasília, Juiz de Fora, Porto Alegre, Recife, São Luís e Rio de Janeiro, respectivamente. Além de verificar tendências, temáticas novas e recorrentes, observamos o processo de estruturação e articulação dos pesquisadores e da produção cientifica em nossa área. Analisamos integralmente os anais impressos do evento de 2000 e cada CD dos quatro últimos ENPESS. Recolhemos um total de 169 artigos sobre a temática em foco.

A dinâmica deste principal evento de pesquisa da área de Serviço Social compreende encontros bienais, intercalados com seminários e oficinas regionais e nacionais. Nos Encontros Nacionais, são apresentadas pesquisas e debatidas temáticas centrais para o Serviço Social, a formação e atuação profissional do/a assistente social. Nas oficinas e nos seminários regionais, são discutidas as diversas dimensões da formação profissional, os desafios postos à pesquisa e à produção do conhecimento.

A organização deste evento de âmbito nacional do Serviço Social vem passando por mudanças em consonância com o processo de amadurecimento e de estruturação da pesquisa e da pós-graduação em nossa área. O XII ENPESS deu passos significativos no sentido de fortalecer as subáreas temáticas. A estrutura do evento compreende organização de colóquios temáticos e apresentação de trabalhos nos grupos Temáticos de Pesquisa (GTPs), cujo processo de criação vem acontecendo há algum tempo ${ }^{6}$.

\footnotetext{
${ }^{5} \mathrm{O}$ Encontro Nacional de Pesquisadores em Serviço Social é realizado a cada dois anos. Tornou-se fundamental espaço de articulação, bem como de capacitação e realização do debate político-acadêmico.

6 Os GTPs constituem estrutura para organizar os pesquisadores e a produção acadêmica da área de Serviço Social, a qual compreende 07 (sete) GTPs, assim designados: 1. Trabalho, Questão Social; 2. Serviço Social, Fundamentos, Formação e trabalho Profissional; 3. Política Social e Serviço Social; 4. Movimentos Sociais e Serviço Social; 5. Questão Agrária, Urbana, Ambiental e Serviço Social; 6.
} 


\section{ACUMULAÇÃO CAPITALISTA E QUESTÃO URBANA: DELINEA- MENTOS PARA FUNDAMENTAR A PERSPECTIVA DE ANÁLISE}

Nos delineamentos teórico-metodológicos que seguem, pretendemos explicitar o norte e, ao mesmo tempo, a posição teórica a partir da qual construímos nossas análises, as quais buscam situar-se em sintonia com o Projeto Ético-Político do Serviço Social. Como destaca Netto (2001), a questão social é corolário do modo capitalista de produção, que se reproduz graças à crescente produção social de riquezas, cuja apropriação privada pela classe dominante remete a classe trabalhadora à condição histórica de explorada, pauperizada, destituída dos frutos de seu trabalho, alienada. A questão social se expressa quando se acirra a contradição entre trabalhadores e proprietários dos meios de produção; quando os trabalhadores, cientes de sua situação de explorados, constroem processos de luta, expondo suas reais condições de vida. Ao nos situarmos no posicionamento histórico coletivo de reforço das lutas sociais, da organização dos trabalhadores numa perspectiva de superação da sociabilidade capitalista, entendemos que tal posição política implica em escolhas teórico-metodológicas inscritas numa perspectiva crítico-dialética. Neste sentido, retomamos, inicialmente, categorias teóricas centrais e explicitamos nossa compreensão da gênese e desenvolvimento da questão urbana nas formações capitalistas.

\section{QUESTÃO URBANA E REPRODUÇÃO CAPITALISTA: POR UMA RE- LEITURA ESPACIAL DO PROCESSO DE ACUMULAÇÃO}

Para situar a temática questão urbana, retomamos aqui a reflexão de David Harvey $(2004 ; 2005)$ visando a integrá-la à nossa análise da lógica capitalista de produção do espaço. Procuramos incorporar contrapontos, debatendo argumentos e textos contemporâneos para construir uma base teórica fundada no método em Marx (1983a), na crítica da economia política que nos permita analisar

a produção acadêmica do Serviço Social brasileiro, sua articulação (ou não) com a perspectiva apontada pelo Projeto Ético-Político da profissão, as contradições, os limites e os desafios que perpassam a construção desta temática de pesquisa. Tratar a questão urbana como particularidade da questão social implica desvelar os meca-

Classe social, gênero, raça/etnia, geração, diversidade sexual e Serviço Social; 7 . Ética, Direitos e Serviço Şocial. 
nismos que participam do processo de reprodução do capital, o qual gera, ao mesmo tempo, acumulação ampliada de riquezas socialmente produzidas, apropriação privada destas, uma totalidade social formada por classes antagônicas em luta.

Com efeito, o desenvolvimento das forças produtivas que conduz à gênese e ao desenvolvimento do modo capitalista de produção apresenta como características intrínsecas a exploração, a apropriação de espaços e a destruição de recursos naturais e da força humana de trabalho com vistas a assegurar o processo de acumulação. Cabe-nos ressaltar que as imposições lógicas da acumulação do capital, as condições da reprodução capitalista - às quais também está submetido o espaço urbano - não podem parecer natural ou descoladas de seu sentido histórico e dinâmico. Ora, essa estrutura existe e se organiza mediada pela luta de classes. Portanto, embora a lógica dominante seja real, efetiva, conformando e moldando o espaço, em nossa condição de seres sociais e históricos, não estamos predestinados a viver perpetuamente em função dessa.

Ao afirmamos imperar uma lógica de organização do espaço inerente ao modo de produção capitalista, estamos, implicitamente, chamando atenção para o conceito de modo de produção. Este não compreende apenas a atividade econômica imediata, mas remete à totalidade da vida social ou, em outros termos, ao conjunto das relações sociais que sustentam o Capitalismo e se estabelecem em determinados períodos históricos e espaços geográficos.

No seio da teoria da acumulação de Marx (MARX, 1983b; 1984a; 1984b), revela-se, assim, a presença de uma dimensão sócio-espacial do modo capitalista de produzir. Nisto, reside o grande mérito teórico da elaboração de David Harvey (2005) ${ }^{7}$. De acordo com estudos deste autor, Marx não desconsidera o contexto geográfico determinado no qual se dá a acumulação do capital. Aliás, não apenas reconhece este aspecto da dinâmica capitalis-

\footnotetext{
7 Para Harvey (2005), a não evidência da dimensão espacial na teoria da acumulação de Marx, ao analisar o modo de produção capitalista, se explica, em parte, pelo fato dos seus escritos sobre o assunto serem fragmentados, mas também por uma certa negligência teórica quanto ao fator mediador da teoria de localização.
} 
ta, mas demonstra que sua lógica engendra estruturas e formas geográficas específicas.

O modo capitalista de produção é, inevitavelmente, expansível, na medida em que "expressa a 'missão histórica da burguesia' na fórmula 'acumulação pela acumulação, produção pela produção"” (HARVEY, 2005, p. 41-42). Daí se relacionar amplamente com as estruturas espaciais. O seu caráter expansível também está presente na afirmação de Marx e Engels n'O Manifesto do Partido Comunista ao apontarem que "[...] a necessidade de mercados sempre crescentes para seus produtos impele a burguesia a conquistar todo o globo terrestre. Ela precisa estabelecer-se, explorar e criar vínculos em todos os lugares" (MARX; ENGELS, 2008, p. 11).

O espaço como produto da atividade humana e da relação homem-natureza faz parte do processo mais geral de reprodução da sociedade. Ao ter sua produção assentada nas necessidades impostas pelo desenvolvimento da acumulação capitalista, o espaço é também mercantilizado, tal como a cidade e a própria moradia, que são, destarte, concebidas como mercadorias necessárias à viabilização da produção, da circulação, distribuição e troca, condição para a realização do ciclo de acumulação do capital. Afinal, sendo o espaço urbano moldado essencialmente para potencializar a acumulação do capital, sua conformação articula as diferentes esferas do modo capitalista de produzir. Exatamente por isso, na produção do espaço, no Capitalismo, há a subsunção do valor de uso ao valor de troca. Em sua particularidade de espaço urbano, este assume duplo papel: lugar de consumo e consumo do lugar (LEFEBVRE, 2001), em um processo no qual o valor de troca prevalece a tal ponto sobre o valor de uso que praticamente suprime este último. Deste modo, "[...] o valor de troca e a generalização da mercadoria pela industrialização tendem a destruir, a subordiná-las a si, a cidade e a realidade urbana, refúgios do valor de uso [...]" (LEFEBVRE, 2001, p. 14).

Apesar de socialmente produzido pela atividade humana criadora, pela qual o homem transforma a natureza e a si mesmo, o espaço é apontado como exterioridade e percebido com estranhamento. Dito de outra maneira, a alienação também está expressa no processo de produção do espaço e das cidades. Para Milton Santos, 
o entendimento do processo de produção do espaço urbano na sociedade capitalista exige-nos apreender:

[...] a forma como atualmente se distribuem as infraestruturas, os instrumentos de produção, os homens - enfim, as forças produtivas - possui até um certo ponto um caráter de permanência, isto é, de reprodução ampliada, amparadas, exatamente, pela longevidade de um grande número de investimentos fixos. Tudo, pois, conspira para que a organização do espaço se perpetue com as mesmas características, favorecendo o crescimento capitalista e suas distorções (SANTOS, 1980, p. 41).

Tal relação não somente impõe determinada configuração ao espaço urbano, como também é indicativa da forma de ocupação do espaço em cada sociedade. Assim, "[...] a cidade e a realidade urbana seriam, nesta hipótese, o lugar por excelência e o conjunto dos lugares onde se realizam os ciclos de reprodução, mais amplos, mais complexos [...] a reprodução das relações [capitalistas] de produção [...]" (LEFEBVRE, 2001, p. 23).

As relações socialmente estabelecidas são também relações espaciais, haja vista encontrarem-se circunscritas no espaço em produção. É, neste, precisamente, em que estão concentrados todos os recursos explorados pelo capital para acumular, a exemplo da força de trabalho e do próprio meio ambiente, com sua diversidade. Desse modo, apreender os mecanismos de reprodução do capital, a partir de sua lógica de acumulação, concentração e expansão, nos permite perceber determinantes para entender a dinâmica urbana.

Nas elaborações de Harvey (2005), encontramos a análise sugerindo ser a acumulação capitalista desenvolvida via articulação de quatro elementos, dentre os quais se destaca a expansão geográfica e a produção do espaço. Os outros três elementos referem-se à intensificação da atividade social: a penetração do capital em novas esferas de atividade; a criação de novas necessidades, desenvolvendo novos produtos; a facilitação e o estímulo ao crescimento populacional.

A expansão geográfica - aspecto para o qual chamamos especial atenção no presente trabalho - figura não somente como condi- 
ção prévia à acumulação capitalista, mas, simultaneamente, como condição e decorrência deste processo, revelando-se também como contraface necessária à acumulação capitalista, que, somada a outros aspectos inerentes à lógica do capital, contribui para aprofundar desigualdades sócio-territoriais. Nesse sentido, nas sociedades capitalistas, a expansão geográfica se traduz em profundas transformações nas cidades e em seus entornos físicos, no meio ambiente e nas relações sociais. Senão, vejamos, a construção de novos portos e aeroportos, nos marcos dos processos de reestruturação produtiva e de mundialização do capital expressam dinâmicas de expansão geográfica da acumulação do capital, com nítidos efeitos sobre as dinâmicas metropolitanas, sobre os recursos ambientais e sobre as relações sociais. Expulsam comunidades tradicionais de áreas litorâneas, extinguem áreas de moradia popular, põem fim a pequenas comunidades rurais que praticam agricultura de subsistência, dentre outros.

Tais transformações, em última instância e sem desconsiderar o próprio teor da luta de classes, não visam a outro objetivo senão moldar a cidade, o espaço urbano às exigências do capital. No processo de acumulação capitalista, o Estado tem desempenhado papel determinante. Como destaca Harvey (2004, p. 80)

O Estado [...] tem tido um papel-chave na acumulação original ou primitiva, usando seus poderes não apenas para formar a adoção de arranjos institucionais capitalistas, mas também para adquirir e privatizar ativos como a base original da acumulação do capital.

Os designados "[...] processos moleculares de acumulação do capital [...]" ocorrem em uma diversidade de escalas geográficas, em ambientes politicamente e hierarquicamente estruturados, beneficiando-se do poder político, de governos e de modalidades de administração territorializadas (HARVEY, 2004, p. 81-82).

Para elucidar a forma como se processa e se caracteriza a acumulação, Harvey (2004) indica a retomada, com distinções, na contemporaneidade, de uma forma arcaica denominada "acumulação por espoliação". Prosseguindo sua reflexão, sugere, ainda, a existência de fontes/espaços de espoliação que se apresentam como externalidades ao capital. Trabalha, assim, com a dialética interior-exterior. 
Segundo o autor, “[...] o capitalismo pode tanto usar algum exterior preexistente (formações sociais não capitalistas, espaços em que a dinâmica de acumulação do capital não se instaurou na sua maior complexidade ou algum setor do capitalismo - como a educação - que ainda não tenham sido proletarizado) como produzi-lo ativamente" (HARVEY, 2004, p. 118).

Virgínia Fontes (2010) polemiza com o termo acumulação por espoliação, forjado por Harvey (2004), por entender que, apesar de extremamente sugestiva, sua tese apresenta algumas dificuldades, ao incorrer no deslize de relegar o tema das expropriações à condição de acumulação primitiva, levando à suposição de que, no amadurecimento do Capitalismo, desapareciam as expropriações bárbaras de sua origem. A discordância de Virgínia Fontes reside, especialmente, no tema da produção de externalidades e na própria contraposição realizada por Harvey (2004) entre espoliação e expropriação. A autora discute o teor contemporâneo das expropriações produzidas - termo considerado mais adequado do que o conceito de espoliação - e seu papel na dinâmica capitalista. Destaca a existência de duas faces da tendência à expansão do capital: a concentração de recursos sociais e as permanentes e recorrentes expropriações. Para a autora:

Expandir relações sociais capitalistas corresponde, portanto, em primeiro lugar, à expansão das condições que exasperam a disponibilidade de trabalhadores para o capital, independentemente da forma jurídica que venha a recobrir a atividade laboral de tais seres sociais. A expropriação primária, original, de grandes massas campesinas ou agrárias, convertidas de boa vontade (atraídas pelas cidades) ou não (expulsas, por razões diversas, de suas terras, ou incapacitadas de manter sua reprodução plena através de procedimentos tradicionais, em geral agrários) permanece e se aprofunda [na atualidade], ao lado de expropriações secundárias [...] (FONTES, 2010, p. 44).

Harvey apresenta as expropriações primárias como pertencentes aos primórdios do Capitalismo, como característica externa a este modo de produção. Tal dinâmica não é reconhecida pelo autor como parte intrínseca do desenvolvimento do capital. Intriga-nos a 
dualidade presente na construção teórica do geógrafo marxista ao abordar esta questão, distinguindo características inerentes à gênese do Capitalismo e outras supostamente estranhas e externas ao seu desenvolvimento.

A dificuldade presente na elaboração de Harvey refere-se, especificamente, à dualidade da categoria espoliação, notadamente, por deixar margem para tomar a espoliação como própria a um estágio de acumulação (primitivo). Nosso processo de pesquisa tem nos levado a entender a expropriação como própria à acumulação capitalista. Ainda que assuma contornos diferenciados nos contextos sociais e geográficos e nos tempos históricos particulares, não deixa de ser parte intrínseca da natureza do Capitalismo. No debate em foco, corroboramos com a posição de Fontes (2010): reafirmamos a coexistência de expropriações primárias e secundárias no processo de acumulação do capital.

No espaço, ocorrem as expropriações e a reapropriação de parcelas a serem "re-funcionalizadas" pelo capital. Interessa-nos, então, saber por meio de que mecanismos as expropriações subjacentes à lógica capitalista se traduzem em transformações nas cidades e nas relações sociais aí estabelecidas.

Entendemos a questão urbana como decorrência das expropriações promovidas pelo processo de acumulação do capital. Esta apresenta facetas particulares da problemática ambiental. Como expressa Bonduki (2012) não se pode falar em questão urbana, na atualidade, sem mencionar os graves problemas ambientais que marcam nossas cidades e, em particular, as cidades dos países de Capitalismo periférico, onde o processo de urbanização intenso e rápido não se fez acompanhar de intervenções do Estado no sentido de normatizar e dotar o espaço de infraestruturas, serviços e equipamentos urbanos no mesmo ritmo de seu acelerado crescimento demográfico e de sua expansão física. As expressões se avolumam para caracterizar os processos de expansão urbana nos países periféricos.

\section{EXPANSÃO URBANA E SEGREGAÇÃO SÓCIO-ESPACIAL}

Para o estudo da forma como se processa e se materializa o fenômeno de ajuste da cidade às exigências do domínio do capital, 
reivindicamos, dentre as produções clássicas e referências obrigatórias das ciências sociais, a obra de Friedrich Engels (2008) em A situação da classe trabalhadora na Inglaterra, dada a relevância dessa para compreender a urbanização capitalista como instrumento particular de segregação espacial e social. Para Engels, a questão urbana e os processos sociais por ela engendrados devem ser entendidos como decorrentes da moderna industrialização capitalista. É neste terreno histórico que Henri Lefebvre situa suas análises. Para o autor, enquanto processo indutor de transformações societárias, a industrialização destaca-se como fenômeno gerador de diversas questões referentes à cidade e à produção da realidade urbana. Isto não significa negar a preexistência da cidade à industrialização. Aliás, quando nasce, o Capitalismo concorrencial com a burguesia especificamente industrial, as cidades já figuravam como centros da vida social e política nos quais se acumulavam riquezas.

Com a Revolução Industrial, a maquinaria expande a produção de vários itens, tanto nas cidades como no campo, desencadeando o crescimento do proletariado industrial e o surgimento do operário mineiro e agrícola. O desenvolvimento industrial faz surgir necessidades de serviços, contribuindo para a expansão das cidades industriais, as quais se tornaram, cada vez mais, dinâmicas e atraentes, aumentando, assim, sua população e modificando paulatinamente sua morfologia. Com a ampliação e densificação, as áreas urbanas comportam contingentes crescentes de trabalhadores, aptos ao trabalho, tidos como supérfluos definitiva ou temporariamente às necessidades médias de acumulação do capital - a designada superpopulação relativa - subsistindo em condições precárias e degradantes. Há tendência ao crescimento de áreas de habitações precárias, desprovidas de infraestrutura e de serviços urbanos (ENGELS, 2008).

$\mathrm{Na}$ cidade, vale a lei do mercado! Aqueles cujos rendimentos permitem, vivem em lugares mais bem equipados, de fácil acesso, com níveis de conforto. Os pobres são relegados à própria sorte. Quando não dormem nas ruas, em lugares perigosos, vivem em áreas distantes dos centros urbanos e com pouca ou nenhuma infraestrutura. Torna-se, cada vez mais, possível expropriar os pobres dos lugares de maior acesso ao que podemos designar de oportunidades urbanas. Ao se referir à segregação sócio-espacial, Maricato (2003) afirma que: 
A segregação urbana ou ambiental é uma das faces mais importantes da desigualdade social e parte promotora da mesma. À dificuldade de acesso aos serviços e infraestrutura urbanos (transporte precário, saneamento deficiente, drenagem inexistente, dificuldade de abastecimento, difícil acesso aos serviços de saúde, educação e creches, maior exposição à ocorrência de enchentes e desmoronamentos, etc.) somam-se menos oportunidades de emprego (particularmente do emprego formal), menos oportunidades de profissionalização, maior exposição à violência (marginal ou policial), discriminação racial, discriminação contra mulheres e crianças, difícil acesso à justiça oficial, difícil acesso ao lazer. A lista é interminável (MARICATO, 2003, p. 152).

O debate teórico explicitado nos parece fundamental para apreendermos as novas dinâmicas urbanas em tempos de mundialização financeira, com suas incidências sobre as cidades e, em particular, sobre as condições de moradia e de vida da classe trabalhadora. Ora, considerando as expropriações - primárias e secundárias - intrínsecas à dinâmica de reprodução do capital, em sua busca incessante de enfrentar suas crises de acumulação, na fase atual de desenvolvimento das forças produtivas, o espaço constitui um fator essencial. As aproximações teórico-metodológicas elaboradas nos guiaram no processo de análise da produção acadêmica do Serviço Social brasileiro relativa à questão urbana, veiculada nos anais dos ENPESS realizados a partir de 2000.

\section{PRODUÇÃOCIENTÍFICADESERVIÇOSOCIALEQUESTÃOURBANA}

A partir da apreciação dos anais, verificamos um nítido crescimento da produção do Serviço Social nas mais variadas temáticas, quando comparado o número de artigos aceitos no ENPESS de 2010 e o quantitativo aceito no ENPESS de 2000 . No encontro de 2010, no computo geral, temos, aproximadamente, um número de artigos 06 (seis) vezes maior do que encontramos em 2000, totalizando, assim, 229 (2000) e 1.293 (2010).

O gráfico a seguir mostra o crescimento da produção apresentada nos ENPESS. 


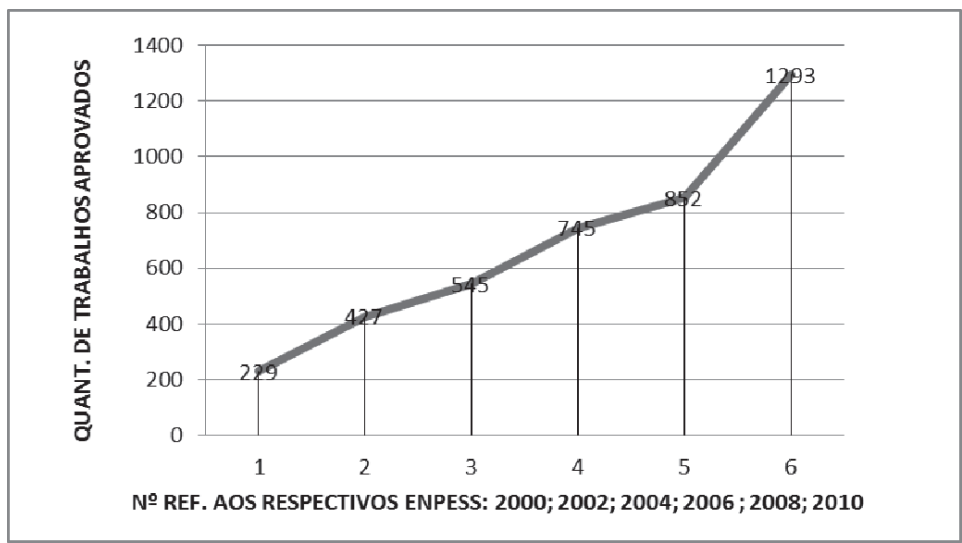

Gráfico 1 - Trabalhos aprovados nos ENPESS de 2000, 2002, 2004, 2006, 2008 e 2010. Elaboração: Raquel Cardozo. Fonte: consulta aos Anais dos ENPESS.

Este crescimento também se expressa na quantidade de trabalhos relacionados à questão urbana e ambiental. Tomando por base a produção de 2000 e aquela de 2010, temos, aproximadamente, um número de trabalhos 03 (três) vezes maior neste último evento, 0 que representa em números 16 artigos (2000) e 49 (2010).

Nesta primeira fase, não procedemos a uma averiguação mais aprofundada do conjunto dos artigos selecionados, que compõem nosso banco de dados. De modo geral, observamos certo avanço na qualidade da produção. Todavia, nos foi possível verificar a existência de elaborações que carecem de consistência teórico-metodológica. Nestas aproximações preliminares, analisamos o conjunto dos artigos do ENPESS de 2010, a partir de leitura orientada.

A análise da natureza e origem das produções sobre questão urbana publicadas nos ENPESS revela a presença de pesquisas de cunho teórico e pesquisas de campo; pesquisas de mestrado em andamento; reflexões provenientes de disciplinas; relatos e discussões oriundas de experiências de estágio. Esta diversidade de trabalhos reforça nosso entendimento acerca do processo de construção do conhecimento, o qual não se limita à mera transmissão de saberes no espaço da sala de aula. Podemos supor que a dimensão investigativa vem se ampliado no âmbito da formação. Contudo, as análises dos dados também indicam a necessidade de continuidade, aprofundamento e divulgação das pesquisas. Algumas apresentam níveis de análise ainda incipientes. Poucas pessoas publicam 
sistematicamente nos ENPESS; aquelas que o fazem, no âmbito do GTP Questão Agrária, Urbana e Ambiental compõem um grupo pequeno de pesquisadores, com maior experiência, em sua maioria, vinculados a grupos de pesquisa em suas universidades. Daí surge o desafio de dar continuidade à pesquisa sobre a temática para maior aproximação com relação ao objeto de estudo, enriquecendo as análises, explicitando as múltiplas determinações da totalidade. Apenas desse modo ampliaremos a capacidade de desvendar contradições essenciais na realidade estudada, avançaremos pistas para novas pesquisas e intervenções na área do Serviço Social em consonância com nosso Projeto Ético-Político.

A tríade Capitalismo-Estado-Neoliberalismo tem perpassado a fundamentação teórica da grande maioria das produções analisadas. Ao mesmo tempo, têm sido muito comuns os diálogos e interfaces dos artigos sobre questão urbana com o temário referente a gênero, movimentos sociais, políticas sociais e mundo do trabalho, numa clara demonstração da articulação inconteste e necessária entre estes distintos aspectos da realidade. Estas interfaces impõem-nos a necessidade de pensar a dinâmica de funcionamento dos GTPs. Os próprios destaques dados pela categoria às condições dos trabalhadores informais nas cidades, em especial o catador de lixo - hoje chamado por muitos "catadores de material reciclável" - mostram a atualidade da problemática e a necessidade de desvelar o discurso sobre o "desenvolvimento sustentável" em evidência na sociedade, especialmente na atualidade.

Nas publicações analisadas, a tradição marxista aparece, como o mais recorrente referencial teórico-metodológico afirmado por assistentes sociais e estudantes em formação para suas elaborações acerca da questão urbana. Nos artigos analisados, os/as pesquisadores/as vêm recorrendo a autores de grande renome na temática a exemplo de: Karl Marx (1983a), Friedrich Engels (2008), Jean Lojkine (1997), Manuel Castells (2000), David Harvey (2004; 2005) e Ermínia Maricato (2003; 2006). Trabalhamos com a hipótese de que a adoção do referencial crítico-dialético constitui importante desdobramento teórico e político para a superação e ruptura com o tradicionalismo, processo que aconteceu (e ainda acontece) no contexto de avanços e limites do Movimento de Reconceituação do Serviço Social. Entretanto, encontramos, ainda, utilização de noções e conceitos em 
voga, em especial, na Sociologia francesa (o debate sobre a exclusão, desfiliação/filiação) de modo acrítico, além de relativo ecletismo, especialmente nas produções do início dos anos 2000. A crítica a noções como "exclusão social”, bem como a modelos analíticos europeus, ainda relativamente recente, não foi apropriada por boa parte dos autores dos trabalhos analisados.

Ao analisar a condição de grande parte da população urbana mundial que vive nas favelas, Maricato a designa de excluída:

[...] a exclusão é um todo: territorial, ambiental, econômica, racial, cultural etc. O solo ilegal parece constituir a base para uma vida ilegal e esquecida pelos direitos e benefícios urbanos (MARICATO, 2006, p. 5).

Estes segmentos da classe trabalhadora, entendidos por nós, não como "excluídos", mas dentro da lógica e da dinâmica capitalista de produção, sofrem todos os determinantes citados pela autora. Tornam-se muito mais vulneráveis sendo, inclusive, forçados não apenas a viver em péssimas condições, mas a receber baixos salários caso tenham "oportunidade" de trabalho. Por isso, particularmente na América Latina, são alvos de “[...] contratadores de mão-de-obra que buscam moradores de favelas urbanas para trabalho temporário ou sazonal no campo" (DAVIS, 2007, p. 55).

Verificamos ainda a presença, em alguns trabalhos, da noção de planejamento urbano como supostamente sendo o cerne da questão. Nestes casos, atribui-se à ausência de "planejamento eficaz" o determinante dos problemas urbanos e, por decorrência, concentra-se neste âmbito sua solução. Há certo reducionismo na discussão de dimensões da questão urbana, cuja resolução demandaria "modelos de planejamento e de gestão", técnicas mais apropriadas, etc. A discussão central dos mecanismos geradores das desigualdades sociais no processo de acumulação do capital é silenciada.

Não podemos olvidar o contingente crescente de trabalhadores morando nas ruas, ocupando calçadas e estacionamentos, marquises de lojas e entradas de edifícios públicos nas principais cidades brasileiras, mas também em cidades de países centrais do Capitalismo, onde é cada vez mais comum encontrar em galerias de metrôs, em prédios vetustos os "pobres" urbanos, aqueles que perdem progressivamente a condição humana. 
No que se refere à produção teórica abordando a relação entre questão urbana e Serviço Social, percebemos duas tendências se delineando: uma primeira, e menos expressiva, de trabalhos publicados, que situa esta relação no plano da dimensão político-organizativa e, uma segunda tendência, bastante frequente nos artigos analisados, que problematiza a relação do Serviço Social com a questão urbana do ponto de vista do exercício profissional.

O aspecto político-organizativo evidencia-se, sobretudo, quando se tratam de elaborações sobre os movimentos sociais urbanos. Nesses casos, a perspectiva apontada tem sido de que a apreensão das contradições urbanas, bem como da ação coletiva de sujeitos sociais, para evitar a degradação das suas condições de vida na cidade, interessa ao Serviço Social; especialmente pelo fato dos direitos sociais serem considerados o solo de inserção do trabalho dos(as) assistentes sociais. Tal interesse torna-se ainda mais premente na medida em que a profissão atua viabilizando o acesso a políticas sociais.

Nessa lógica, no atual cenário de regressão de direitos, uma atuação profissional pautada na perspectiva da racionalidade crítico-dialética (GUERRA, 2004) e em consonância com o projeto profissional tem como uma de suas premissas a necessidade de conhecer os movimentos sociais que atuam naquele contexto, bem como pressupõe "[...] ações voltadas ao fortalecimento dos sujeitos coletivos, dos direitos sociais e a necessidade de organização para a sua defesa, construindo alianças com os usuários dos serviços na sua efetivação" (IAMAMOTO, 2010, p. 199-200). Os trabalhos que abordam esta dimensão em suas análises têm, portanto, destacado a imensa possibilidade dos(as) profissionais de Serviço Social contribuírem para o fortalecimento da atuação e formação política dos movimentos sociais urbanos.

Sob a ótica do exercício profissional, os trabalhos analisados priorizaram discutir as experiências contemporâneas de inserção e atuação do(a) assistente social em Secretarias Municipais de Habitação e seus respectivos programas habitacionais. Sinalizam a necessidade de ampliar cada vez mais a inserção da profissão nesse espaço sócio-ocupacional, haja vista a política urbana constituir um mecanismo importante na efetivação de direitos sociais e um espaço de inserção, em crescimento, a demandar profissionais com com- 
petência teórico-metodológica, ético-política e técnico-operativo. O debate sobre a questão da habitação com maior expressão na categoria representa o que se mostra para o Serviço Social de forma mais latente nesta temática: a ausência de um lar, as péssimas condições de moradia da população pauperizada, as remoções, os conflitos entre segmentos da classe trabalhadora, o capital fundiário e imobiliário urbano, mediados pelo Estado. Ao mesmo tempo, evidencia os limites da política de habitação, na qual assistentes sociais são chamados a atuar no desenvolvimento de seus programas e projetos. Cabe ressaltar que, historicamente, a problemática da habitação constituiu campo importante de preocupação e atuação de profissionais do Serviço Social, como ademais de áreas afins (Arquitetura, Planejamento Urbano, Ciências Sociais, Geografia).

Referindo-se à realidade brasileira, Maricato (2003) chama a atenção para a dimensão da questão habitacional enquanto particularidade da questão urbana e ambiental. Para a autora, qualquer análise, ainda que superficial, das cidades brasileiras revela essa relação direta entre moradia pobre e degradação ambiental. Isto não quer dizer que a produção imobiliária privada ou que o Estado, ao promover a produção do espaço, não cause danos ao meio ambiente. Os exemplos de aterramento de mangues em todo o litoral do país para a construção de condomínios de veraneio e de áreas de lazer são fartos. A autora cita ainda as indefectíveis avenidas de fundo de vale com canalizações de córregos tão ao gosto dos prefeitos municipais e de certa engenharia "das empreiteiras". Grande parte das áreas urbanas de proteção ambiental encontra-se ameaçada pela ocupação, com uso habitacional, por trabalhadores pauperizados, por absoluta falta de alternativas. As consequências de tal processo atingem toda a cidade, mais especialmente os trabalhadores pauperizados que ocupam áreas de proteção ambiental, espaços públicos não urbanizados e/ou protegidos, alternativa para abrigar-se com suas famílias.

Em alguns casos, constatamos um debate ainda superficial do objeto, no que concerne ao desenvolvimento teórico-metodológico. $\mathrm{O}$ caráter incipiente de algumas produções nos preocupa e nos leva a problematizar a consistência e pertinência de alguns resultados apresentados. Ora, a realização sistemática de pesquisas revela-se fundamental para uma aproximação crítica com o movimento do 
real, para, assim, apreender o máximo de determinações do objeto estudado. Entendemos que, deste modo, podemos identificar tendências e desafios teóricos e práticos postos ao Serviço Social brasileiro nestes tempos contemporâneos.

Algumas produções não ultrapassam o caráter descritivo e as dimensões técnicas. Podemos destacar, entretanto, que, em sua maioria, os artigos apresentam certo avanço na qualidade da produção socializada nos eventos, a qual corresponde a um esforço empreendido pela categoria, nos últimos anos, capitaneado pelas entidades representativas e graças à ação dos programas de pós-graduação. Como destaca Sposati (2007, p. 17):

[...] ocorreu grande esforço nas décadas de 80 e 90 em fortalecer a base científico-profissional difundida, principalmente, através do processo de desconstrução e reconstrução crítica da profissão e de seu exercício, fundando-se no aporte sócio-histórico da análise do real, que foi disseminado pelo então 'novo' currículo de formação da década de 80. Esse processo permeou a categoria pela academia, centros de formação, coletivos profissionais, encontros, debates, publicações, congressos. Foi efetivamente a construção da nova cultura crítica no âmbito da profissão e da formação profissional que tem o mérito desse fortalecimento da pesquisa para os assistentes sociais (SPOSATI, 2007, p. 17).

Todo o esforço empreendido pela categoria em formar profissionais críticos e comprometidos com a pesquisa de forma a desvendar o movimento do real parece se materializar na produção do conhecimento em nossa área. Evidente: os diversos campos temáticos de pesquisa e de atuação têm se desenvolvido de modo bastante heterogêneo, com grande expansão e aprofundamento em áreas historicamente mobilizadoras de nossa categoria, a exemplo da assistência e das políticas sociais. De todo modo, grande parte dos trabalhos levantados buscam problematizar de forma crítica os objetos estudados.

Os recortes estabelecidos nas pesquisas analisadas refletem tentativas de apreensão do que emerge nas cidades, na realidade urbana e que se mostra como expressão da questão social. Destacamos a importância destas produções para entendermos a ques- 
tão urbana, especialmente a produção dos autores que problematizam sob perspectiva crítica, não descolando o particular do universal. Tais produções têm contribuído para a apreensão com maior nível de complexidade da dimensão urbana da totalidade social, em sua particularidade histórica representada pela realidade brasileira contemporânea.

\section{CONSIDERAÇÕES FINAIS}

A questão urbana se expressa de forma contundente nas cidades na ausência de moradia, nas condições degradantes de habitação, violência urbana, catástrofes ambientais e sociais, evidenciada na luta dos movimentos sociais. A temática vem ganhado cada vez mais espaço na sociedade e isso se reflete nos espaços de atuação do Serviço Social, no crescimento do número de pesquisas problematizando tais expressões da questão social.

Entendemos que a realidade urbana brasileira em sua diversidade não pode ser desconsiderada pelo Serviço Social. Ora, dados do IBGE (2011) indicam que 160.879.708 habitantes compõem a população urbana, correspondendo a 84,4\% em 2010 do total da população brasileira. Estes habitantes em situação urbana encontram-se concentrados, sobretudo, nas áreas metropolitanas e nas maiores aglomerações urbanas. Com efeito, o acréscimo de quase 23 milhões de habitantes urbanos explica o aumento do grau de urbanização, constatado no censo de 2010, o qual indica que a população urbana brasileira passou de $81,2 \%$ em 2000 , para $84,4 \%$ em 2010 . Esse incremento decorre do próprio crescimento vegetativo nas áreas urbanas, além das migrações com destino urbano. Podemos falar em áreas milionárias em termos de concentração de população urbana e em vastas áreas marcadamente rurais e agrárias; a expansão do agronegócio, da produção de cana de açúcar para a produção do álcool combustível, segue expropriando pequenos agricultores, promovendo a grande concentração de terras e a superexploração do trabalho. Estes elementos nos chamam a atenção para a complexidade da questão urbana e rural em nosso país neste início de século XXI. Em se tratando de um país de dimensões continentais, vivenciando temporalidades distintas do processo de reestruturação produtiva, com repercussões particulares nas áreas urbanas e 
rurais, os dados do censo de 2010 revelam a complexidade da questão urbana e rural ${ }^{8}$.

O estudo realizado indica e reforça a indissociabilidade entre questão urbana, agrária e ambiental, todas diretamente ligadas ao desenvolvimento das forças produtivas e às relações de produção conflituosas na sociabilidade capitalista. Em seu processo de acumulação, o capital procede concentrando riquezas e se expandindo geograficamente, sobretudo via expropriações. Como destaca Fontes (2010, p. 11), nossa tarefa essencial, neste início de milênio, consiste em buscar "[...] capturar o movimento histórico do capital, que sem cessar altera as condições da vida social, exacerba contradições e promove novas tragédias socioambientais ao procurar expandir-se ilógica e absurdamente".

Neste primeiro momento de nossa pesquisa, não foi possível analisar mais a fundo a construção teórico-metodológica do Serviço Social sobre a temática, no entanto, os dados analisados permitem concluir que a categoria tem acompanhado e refletido sobre as expressões da problemática urbana de maneira a contribuir para o entendimento das expressões da questão social, estando, assim, produzindo conhecimento relevante socialmente. Além disso, a agenda de pesquisa do Serviço Social no âmbito da questão urba-

${ }_{8}^{8}$ No período intercensitário, 2000/2010, a população residente no conjunto dos 27 municípios das capitais apresentou um crescimento médio anual de 1,17\%, ou seja, semelhante àquele observado para os demais municípios. Em geral, as capitais das Regiões Norte e Nordeste cresceram mais que os demais municípios de suas respectivas Unidades da Federação, com exceção do Pará, Maranhão, Rio Grande do Norte e Pernambuco. No Tocantins foi constatada a maior diferença entre as taxas de crescimento: Palmas figura como a capital que mais cresceu no Brasil, apresentando uma taxa de $5,21 \%$, enquanto os demais municípios do estado cresceram 1,25\% ao ano. Na Região Sul, Curitiba e Florianópolis cresceram mais que o conjunto dos demais municípios de seus estados; Porto Alegre - capital com o menor índice de crescimento populacional (0,35\% ao ano) - cresceu menos que os demais municípios do Rio Grande do Sul. Na Região Centro-Oeste, com exceção de Mato Grosso do Sul, o crescimento dos municípios das capitais foi menor que o dos demais municípios, ocorrendo o mesmo em todos os estados do Sudeste. As Regiões Norte e Nordeste ainda apresentam os menores índices de urbanização comparadas às demais. As mais populosas unidades da Federação são também aquelas que concentram maiores níveis de população urbanas. Destacamos aqui: São Paulo (39 585 251); Minas Gerais (16 715 212); Rio de Janeiro (15 464 239); Bahia (10 102 476); e Rio Grande do Sul (9 100 291). A Bahia (3 914 430) desponta como a Unidade da Federação que concentra a maior população rural, seguida de Minas Gerais (2 882 114), Maranhão (2 427 640), Pará (2 389 492) e Ceará (2 105 824). 
na indica a riqueza temática que instiga e motiva os interesses dos pesquisadores da área e sugere as possibilidades de compreensão da densidade histórica e teórica de nossa profissão.

Acreditamos que a criação dos GTP's por parte da Associação Brasileira de Ensino e Pesquisa em Serviço Social (ABEPSS) contribuirá significativamente para o fortalecimento da atividade de pesquisa no Serviço Social, processo fundamental para impulsionar também novas investigações acerca do temário da questão urbana - um dos eixos dos GTP's - na proporção em que sua organização tende a viabilizar a articulação de pesquisadores dedicados a este mesmo campo de estudos, impulsionando inclusive produções acadêmicas de intercâmbio entre eles.

Permanecem, evidentemente, diversos desafios para a produção do conhecimento numa perspectiva dialética e de totalidade. Continua a desafiar-nos a realização de pesquisas de cunho crítico em um tempo em que nossas análises se defrontam com convites constantes à fragmentação da realidade e à negação de sua totalidade, oscilando entre um viés analítico ausente de sujeitos sociais ou centrado na autonomização do sujeito, tomado como indivíduo isolado e descontextualizado. Defrontamo-nos, ainda, com posturas analíticas insuficientes para dar conta da complexidade da realidade social. Nesse sentido, o esforço teórico e político de revigoramento da concepção de ciência que prioriza a historicidade dos fenômenos e dos processos segue a instigar-nos como provocação.

\section{REFERÊNCIAS}

CASTELLS, Manuel. A questão urbana. Rio de Janeiro: Paz e Terra, 2000.

DAVIS, Mike. Planeta Favela. Tradução de Beatriz Medina. São Paulo: Boitempo, 2007.

ENGELS, Friedrich. A situação da classe trabalhadora na Inglaterra. Tradução B. A. Schuman. São Paulo: Boitempo, 2008.

FONTES, Virgínia. O Brasil e o capital-imperialismo: teoria e história. 2. ed. Rio de Janeiro: EPSJV/UFRJ, 2010.

GUERRA, Yolanda. No que se sustenta a falácia de que na prática a teoria é outra? In: ENCONTRO NACIONAL DE PESQUISADORES 
EM SERVIÇO SOCIAL, 9., 2004, Porto Alegre. Anais... Porto Alegre: ENPESS, 2004. 1 CD-ROM.

HARVEY, David. A produção capitalista do espaço. São Paulo: Annablume, 2005.

. O novo imperialismo. São Paulo: Loyola: 2004.

IAMAMOTO, Marilda Vilela. Serviço Social em tempo de capital fetiche: capital financeiro, trabalho e questão social. 2. ed. São Paulo: Cortez, 2010.

IBGE. Sinópse do Censo Demográfico 2010. Rio de Janeiro, 2011. KOWARICK, Lúcio. A espoliação urbana. Rio de Janeiro: Paz e Terra, 1979.

LEFEBVRE, Henri. O direito à cidade. Trad. Rubens Eduardo Frias. São Paulo: Centauro, 2001.

LOJKINE, Jean. O Estado Capitalista e a Questão Urbana. São Paulo: Martins Fontes, 1997.

MARICATO, Ermínia. Metrópoles brasileiras. Texto elaborado por ocasião da palestra dada no evento Próximo Ato 2006 no dia 26 out. 2006, no Instituto Goethe, por solicitação do Itaú Cultural.

. Metrópole, legislação e desigualdade. Estudos avançados, São Paulo, v. 17, n. 48, p. 151-166, maio/ago. 2003.

MARX, Karl. Contribuição à crítica da economia política. 2. ed. Tradução de Maria Helena Barreiro Alves. São Paulo: Martins Fontes, $1983 a$.

MARX, Karl. O Capital: vol. I, tomo 1. São Paulo: Abril Cultural, 1983b. MARX, Karl. O Capital: vol. I, tomo 2. São Paulo: Abril Cultural, 1984a. MARX, Karl. O Capital: vol. III, tomo 1. São Paulo: Abril Cultural, 1984b. MARX, Karl; ENGELS, Friedrich. Manifesto do Partido Comunista. São Paulo: Expressão Popular, 2008.

NETTO, José Paulo. Cinco notas a propósito da "questão social". Temporalis, Brasília, ano 2, n. 4, p. 41-49, jul./dez. 2001.

BONDUKI, Nabil. A sustentabilidade das cidades e a Rio+20. Le monde Diplomatique Brasil, São Paulo, n. 59, 1 jun. 2012. Disponível 
em: <http://www.diplomatique.org.br/artigo.php?id=1184>. Acesso em : 10 set. 2012.

SANTOS, Milton. Reformulando a sociedade e o espaço. Revista de Cultura Vozes, São Paulo, 1980.

SPOSATI, Aldaíza. Pesquisa e produção do conhecimento no campo do serviço social. Rev. Katálysis, Florianópolis, v. 10, n. esp., p. 15-25, 2007. 